RIVAS Final Conference

"Vibrations - Ways out of the annoyance"

Brussels, 21 November 2013

\title{
Stiff wave barriers for the mitigation of railway induced vibrations
}

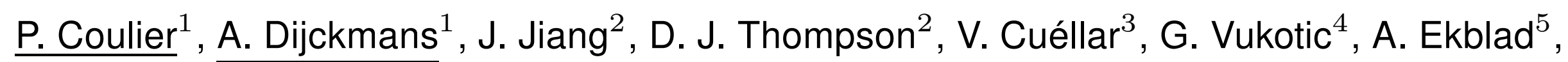
G. Degrande ${ }^{1}$, and G. Lombaert ${ }^{1}$

\footnotetext{
1 KU Leuven, Department of Civil Engineering, Belgium

2 Institute of Sound and Vibration Research, University of Southampton, United Kingdom

3 CEDEX, Spain

4 Keller Cimentaciones, Spain

5 Trafikverket, Sweden
} 


\section{Introduction}

\section{Stiff wave barriers}

- Two types of stiff wave barriers are considered in this presentation:

- Jet grouting wall
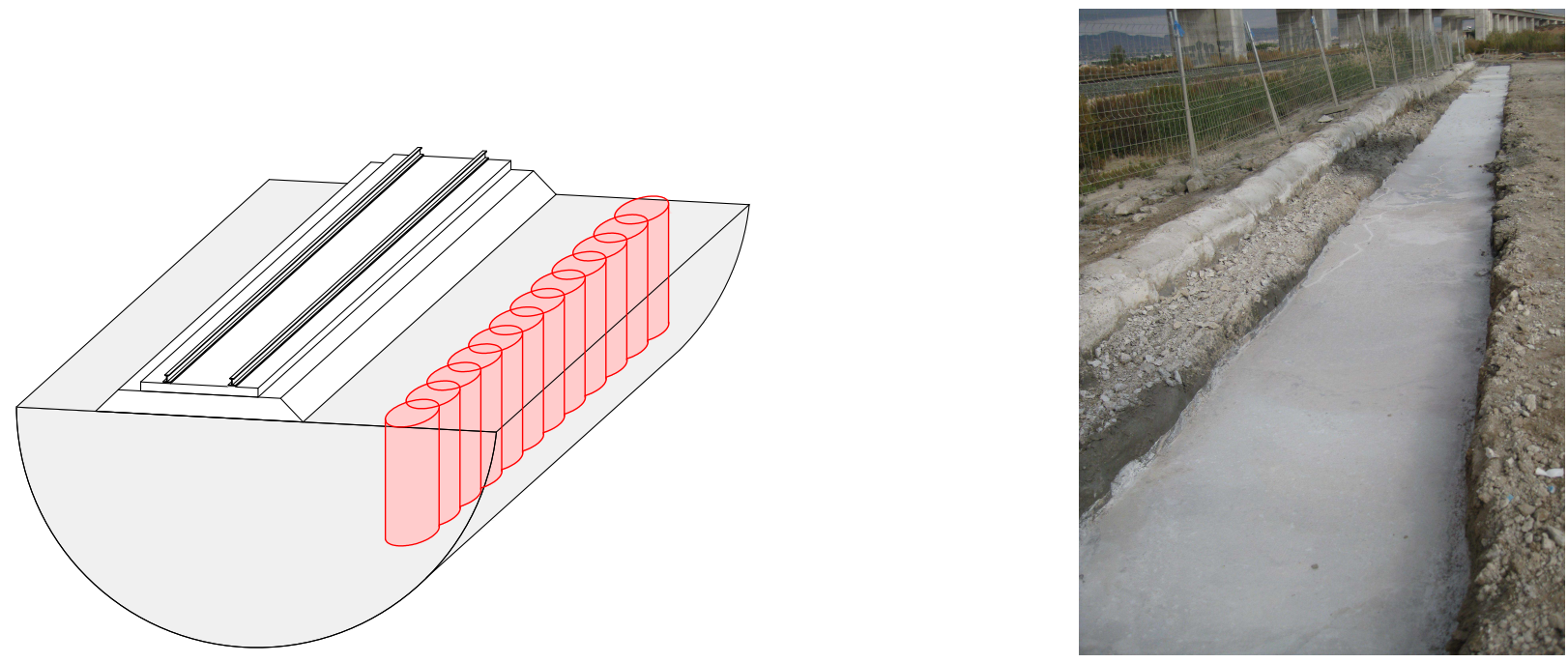

- Sheet piling wall
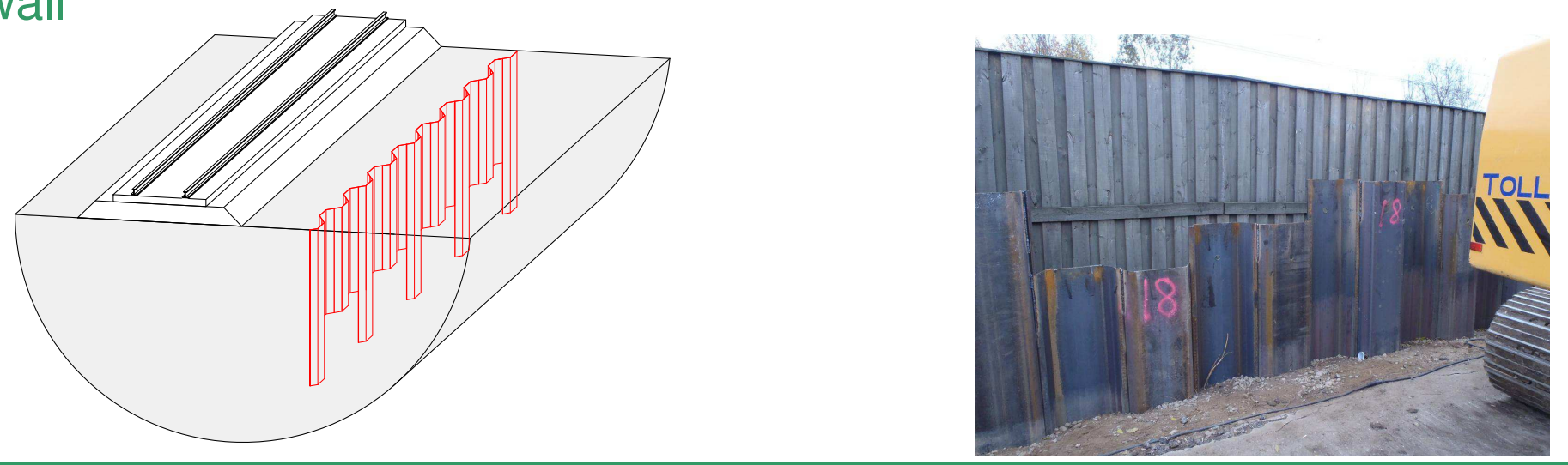


\section{Jet grouting wall}

\section{Stiff wave barrier next to the track}

- Jet grouting wall ( $w=h=2 \mathrm{~m}$ ) in a homogeneous halfspace
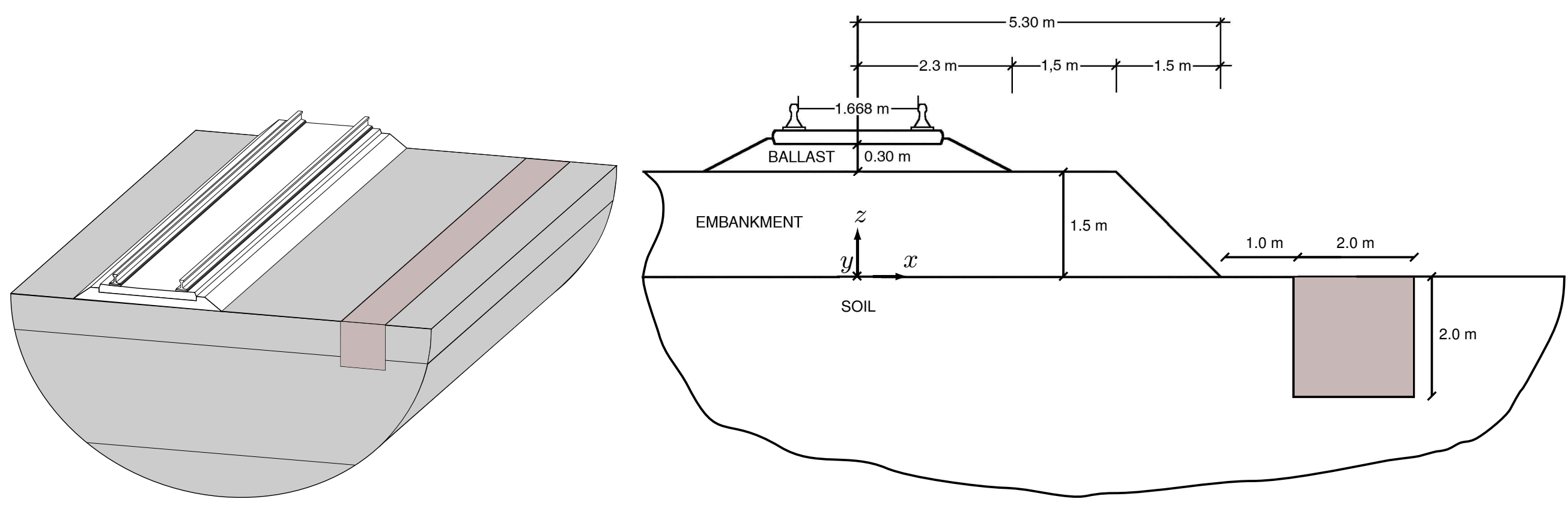

\begin{tabular}{lccccc}
\hline & $C_{\mathrm{s}}$ & $C_{\mathrm{p}}$ & $\beta_{\mathrm{s}}$ & $\beta_{\mathrm{p}}$ & $\rho$ \\
{$[\mathrm{m} / \mathrm{s}]$} & {$[\mathrm{m} / \mathrm{s}]$} & {$[-]$} & $\begin{array}{c}\rho \\
{[-]}\end{array}$ & {$\left[\mathrm{kg} / \mathrm{m}^{3}\right]$} \\
\hline Halfspace & 200 & 400 & 0.025 & 0.025 & 2000 \\
Stiffened soil & 550 & 950 & 0.05 & 0.05 & 2000 \\
\hline
\end{tabular}




\section{Transfer functions}

- Real part of the vertical displacement field $\hat{u}_{z}(\mathbf{x}, \omega)$ at $5 \mathrm{~Hz}$ without barrier

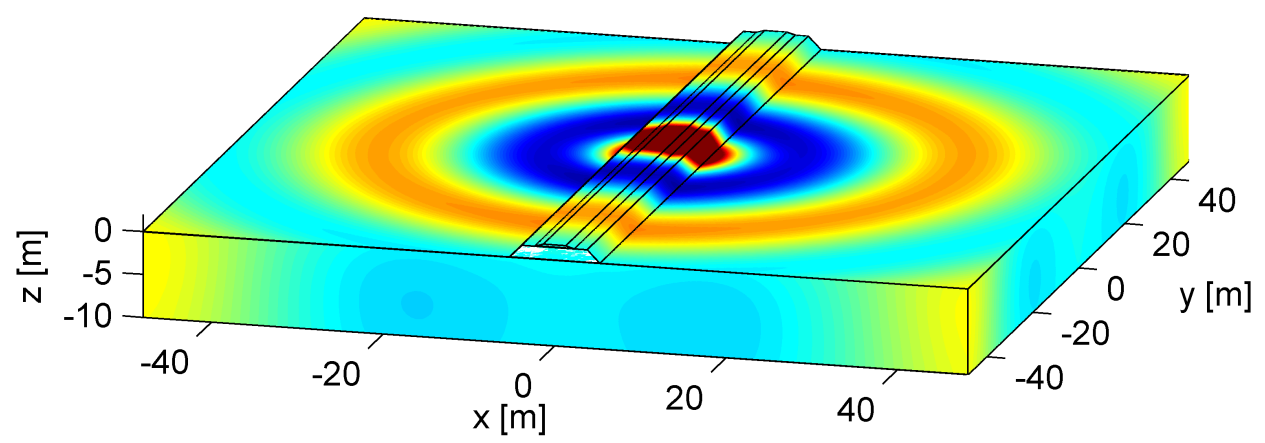

with barrier

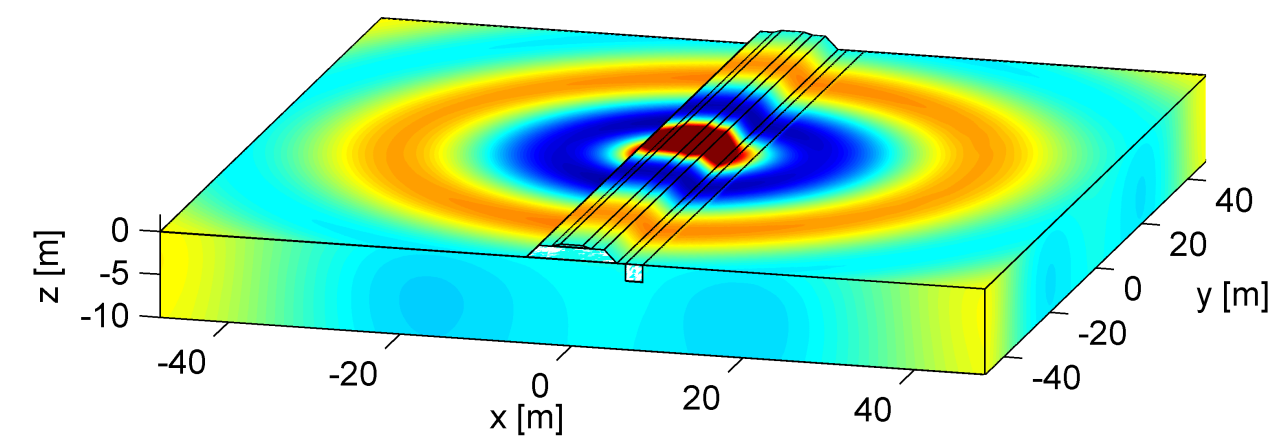

- Corresponding insertion loss $\widehat{\mathrm{IL}}_{z}(\mathbf{x}, \omega)=20 \log _{10} \frac{\left|\hat{u}_{z}^{\mathrm{ref}}(\mathbf{x}, \omega)\right|}{\left|\hat{u}_{z}(\mathbf{x}, \omega)\right|}$

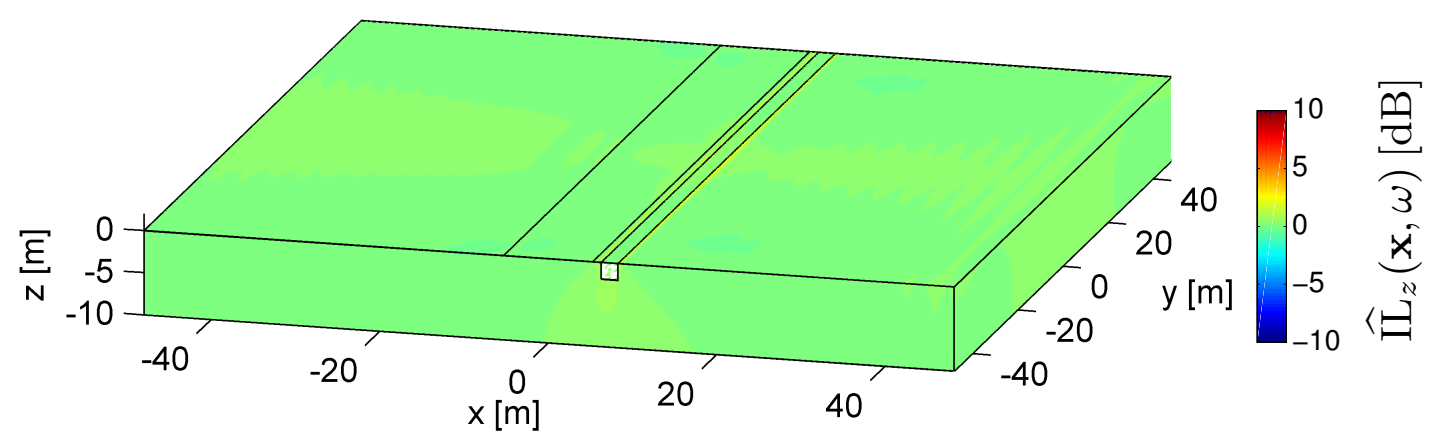




\section{Transfer functions}

- Real part of the vertical displacement field $\hat{u}_{z}(\mathbf{x}, \omega)$ at $30 \mathrm{~Hz}$ without barrier

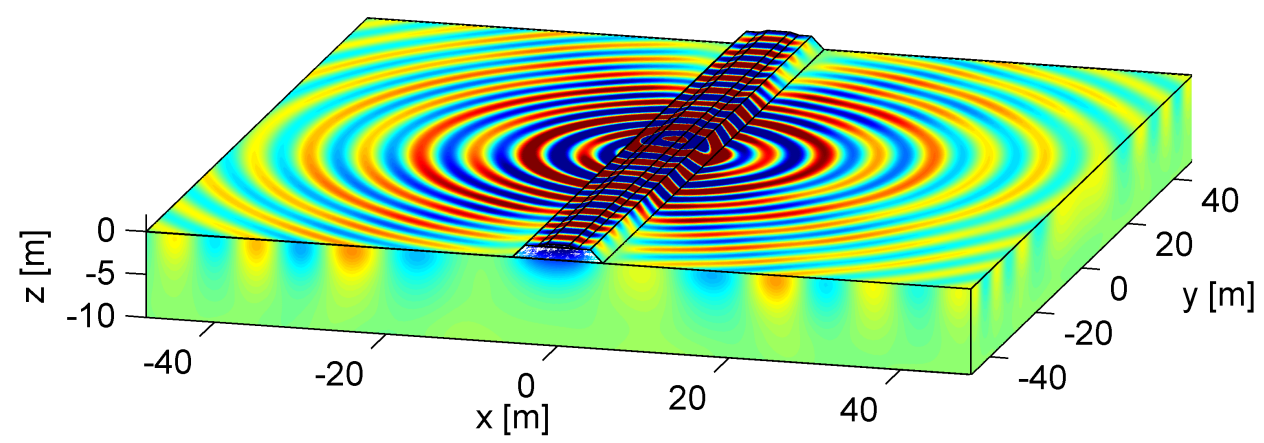

with barrier

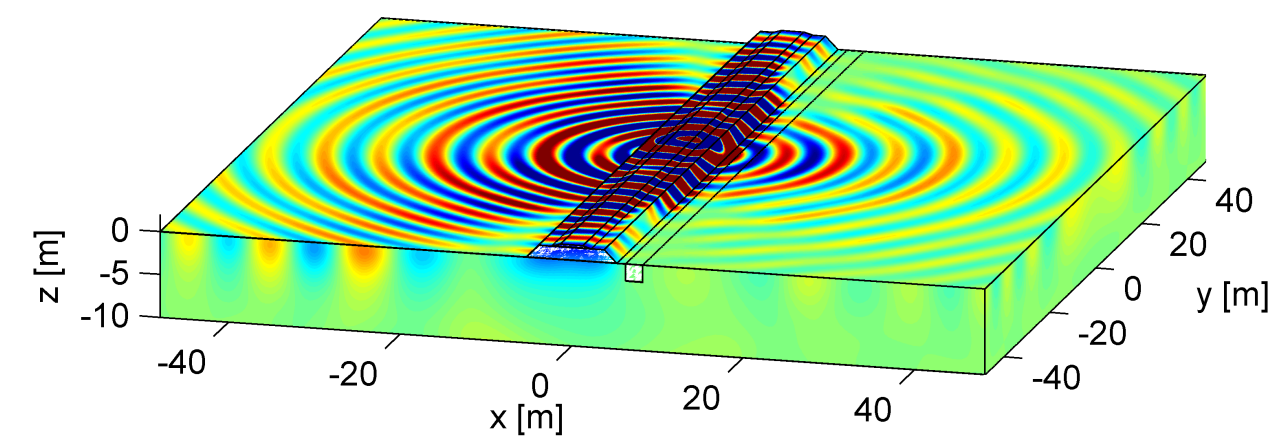

- Corresponding insertion loss $\widehat{\mathrm{IL}}_{z}(\mathbf{x}, \omega)=20 \log _{10} \frac{\left|\hat{u}_{z}^{\text {ref }}(\mathbf{x}, \omega)\right|}{\left|\hat{u}_{z}(\mathbf{x}, \omega)\right|}$

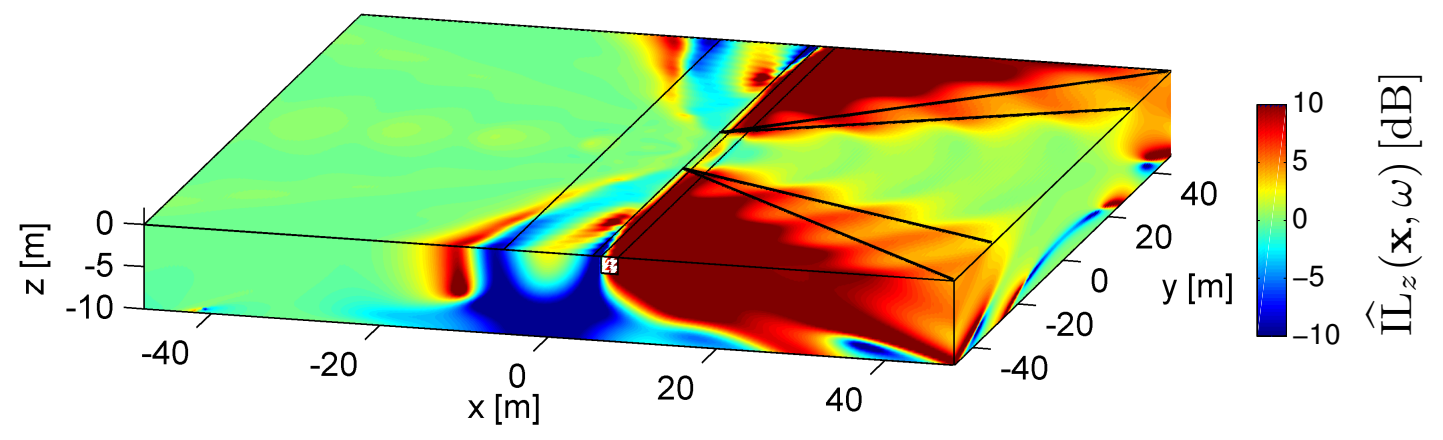




\section{Transfer functions}

- Real part of the vertical displacement field $\hat{u}_{z}(\mathbf{x}, \omega)$ at $60 \mathrm{~Hz}$ without barrier

with barrier
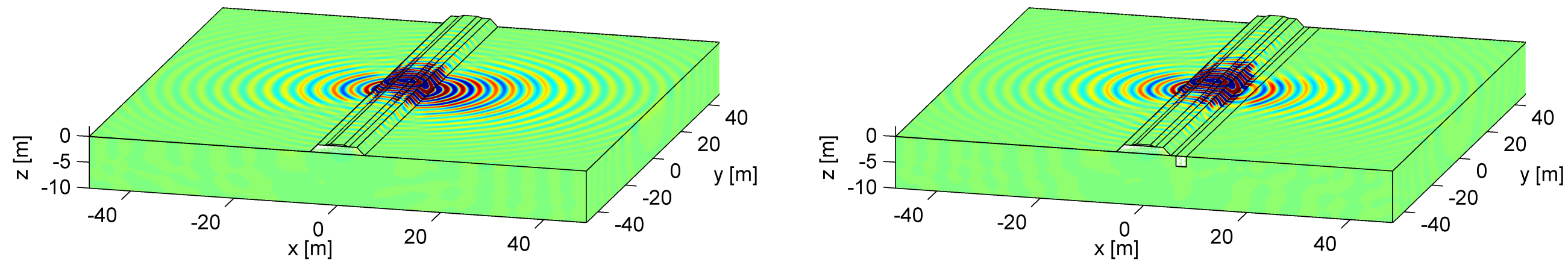

- Corresponding insertion loss $\widehat{\mathrm{IL}}_{z}(\mathbf{x}, \omega)=20 \log _{10} \frac{\left|\hat{u}_{z}^{\text {ref }}(\mathbf{x}, \omega)\right|}{\left|\hat{u}_{z}(\mathbf{x}, \omega)\right|}$

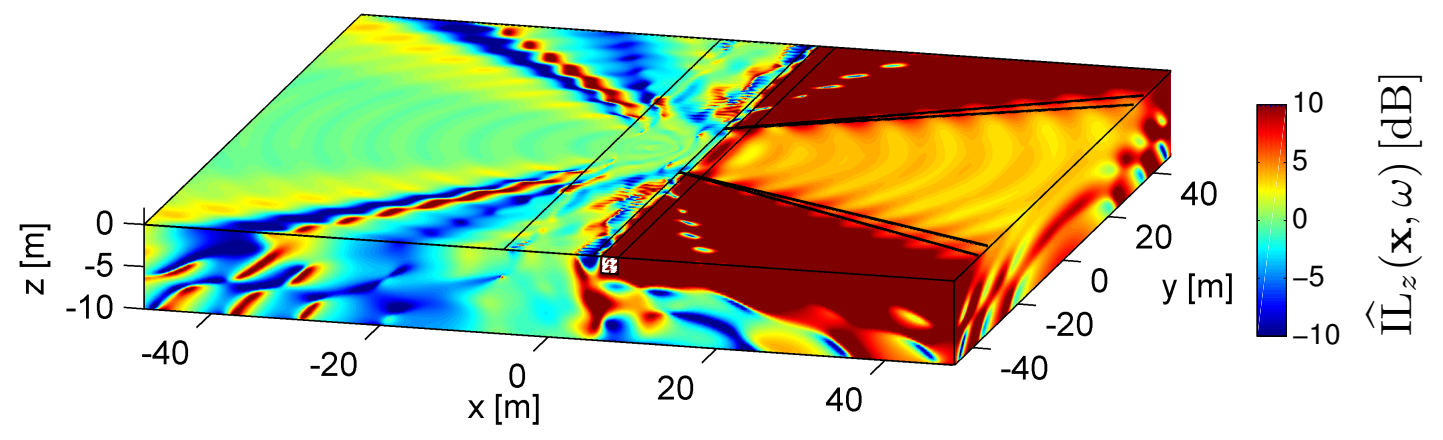




\section{Transfer functions}

\section{Interaction of Rayleigh waves in the soil and bending waves in the stiff wave barrier}

- Cylindrical wavefield can be decomposed into plane waves, satisfying the dispersion relation $\frac{1}{\lambda_{x}^{2}}+\frac{1}{\lambda_{y}^{2}}=\frac{1}{\lambda_{\mathrm{R}}^{2}}$, where $\lambda_{\mathrm{R}}=2 \pi \frac{C_{\mathrm{R}}}{\omega}$ is the Rayleigh wavelength.
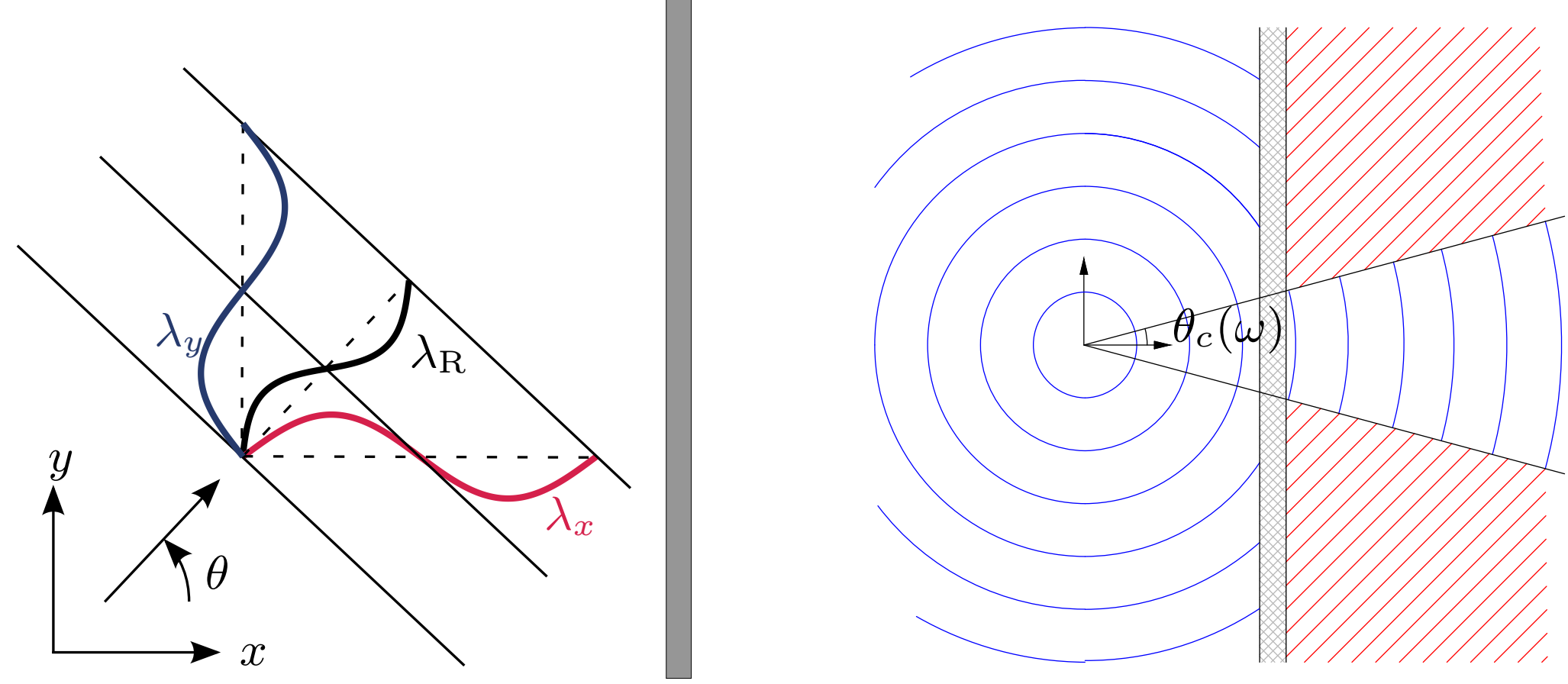

- Propagating plane waves are characterized by $\lambda_{\mathrm{R}} \leqslant \lambda_{y} \leqslant \infty$ :

$-\theta=0 \Rightarrow \lambda_{x}=\lambda_{\mathrm{R}}, \lambda_{y}=\infty$

$-\theta=\pi / 2 \Rightarrow \lambda_{y}=\lambda_{\mathrm{R}}, \lambda_{x}=\infty$ 


\section{Transfer functions}

\section{Interaction of Rayleigh waves in the soil and bending waves in the stiff wave barrier}

- Rayleigh wave dispersion curve (black line):

$$
\lambda_{\mathrm{R}}=2 \pi \frac{C_{\mathrm{R}}}{\omega}
$$

- Free bending wave dispersion curve (red line):

$$
\lambda_{\mathrm{b}}=\frac{2 \pi}{\sqrt{\omega}}\left(\frac{E I}{\rho A}\right)^{1 / 4}
$$

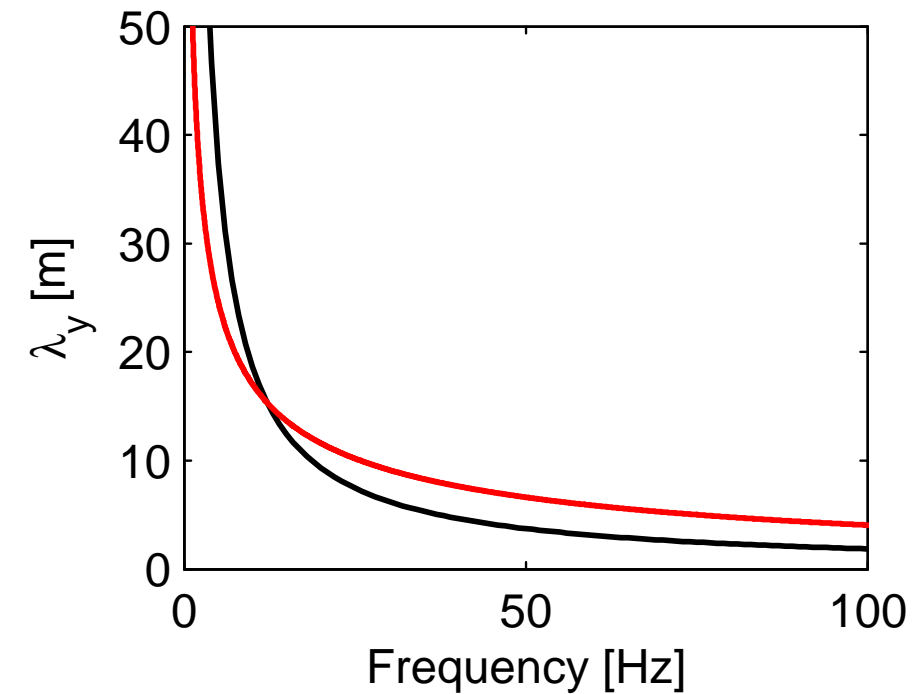

- $f<f_{\mathrm{c}}: \lambda_{\mathrm{b}}<\lambda_{\mathrm{R}} \Rightarrow$ Rayleigh waves propagate unhindered through the block of stiffened soil

- $f>f_{\mathrm{c}}: \lambda_{\mathrm{b}}>\lambda_{\mathrm{R}} \Rightarrow$ wavefield is partially transmitted, partially blocked

$-\lambda_{y}>\lambda_{\mathrm{b}}$ : plane waves are transmitted

$-\lambda_{y}<\lambda_{\mathrm{b}}$ : transmission of plane waves is impeded by the block of stiffened soil

- Critical frequency $f_{\mathrm{c}}$ :

$$
f_{\mathrm{c}}=\frac{C_{\mathrm{R}}^{2}}{2 \pi h} \sqrt{\frac{12 \rho}{E}}=12 \mathrm{~Hz}
$$

- Critical angle $\theta_{\mathrm{c}}(\omega)=\sin ^{-1}\left(\lambda_{\mathrm{R}} / \lambda_{\mathrm{b}}\right)$ :

$$
\sin \theta_{\mathrm{c}}(\omega)=\frac{C_{\mathrm{R}}}{\sqrt{\omega h}}\left(\frac{12 \rho}{E}\right)^{1 / 4}
$$




\section{Train passage}

\section{Passage of a Renfe S599 train at $160 \mathrm{~km} / \mathrm{h}$}
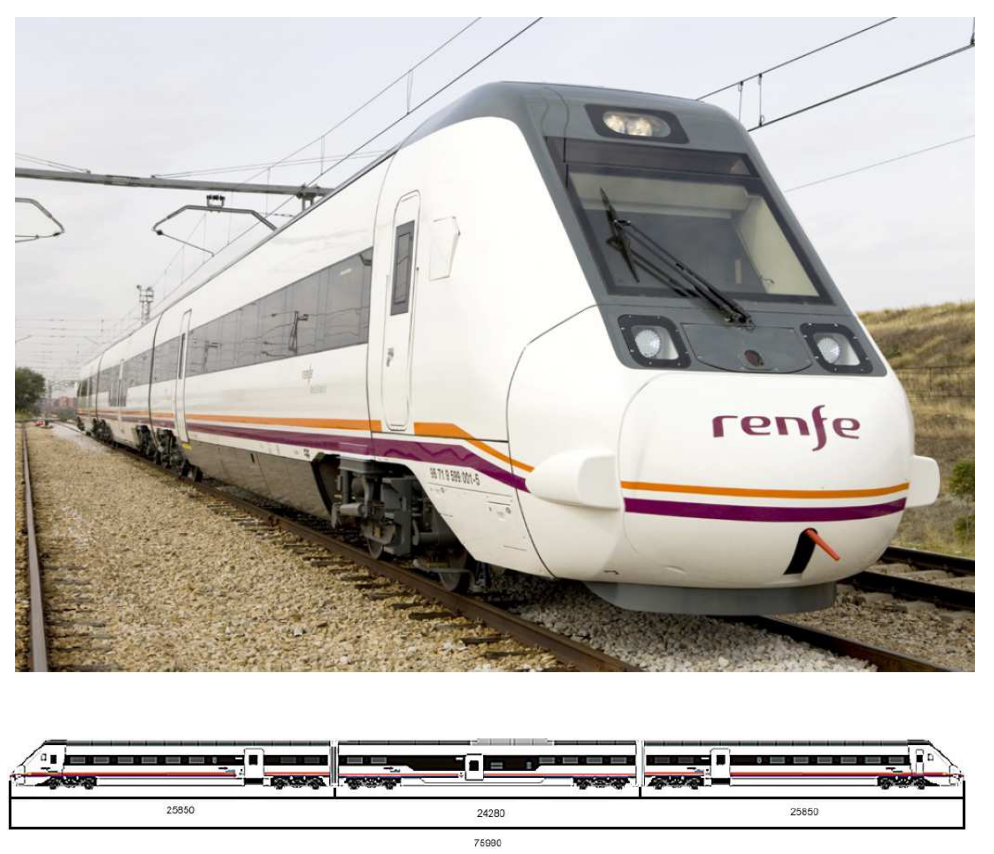

- Simplified model: only the unsprung masses are taken into account

\begin{tabular}{cccccc}
\hline & $N_{\mathrm{a}}$ & $L_{\mathrm{t}}$ & $L_{\mathrm{b}}$ & $L_{\mathrm{a}}$ & $M_{\mathrm{u}}$ \\
{$[-]$} & {$[\mathrm{m}]$} & {$[\mathrm{m}]$} & {$[\mathrm{m}]$} & {$[\mathrm{kg}]$} \\
\hline Two motor coaches & 4 & 25.85 & 17.73 & 2.50 & 1940 \\
One central carriage & 4 & 24.28 & 18.00 & 2.50 & 1704 \\
\hline
\end{tabular}

- Hertzian contact spring $\left(k_{\mathrm{Hz}}=3 \times 10^{9} \mathrm{~N} / \mathrm{m}\right)$; FRA track unevenness (class 3 ) 


\section{Train passage}

Passage of a Renfe 5599 train at $160 \mathrm{~km} / \mathrm{h}$

- One-third octave band RMS spectra of the vertical free field vibrations in the reference case (blue lines) and in case of stiffening next to the track (red lines)

- In case of subgrade stiffening next to the track, a reduction of vibration levels is obtained from the critical frequency of $12 \mathrm{~Hz}$ on.

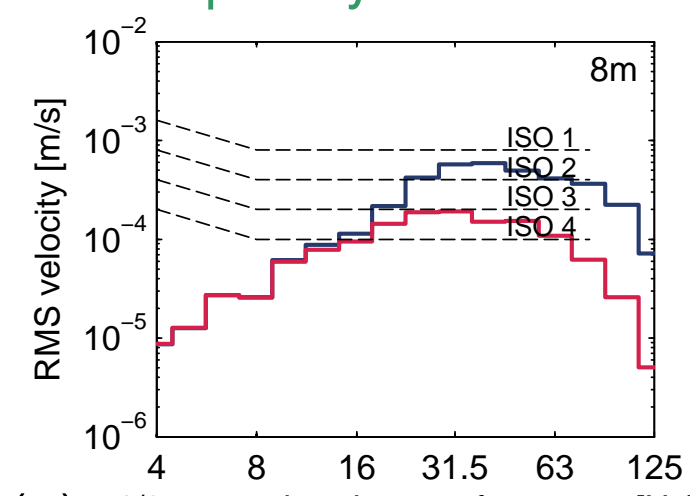

(a)

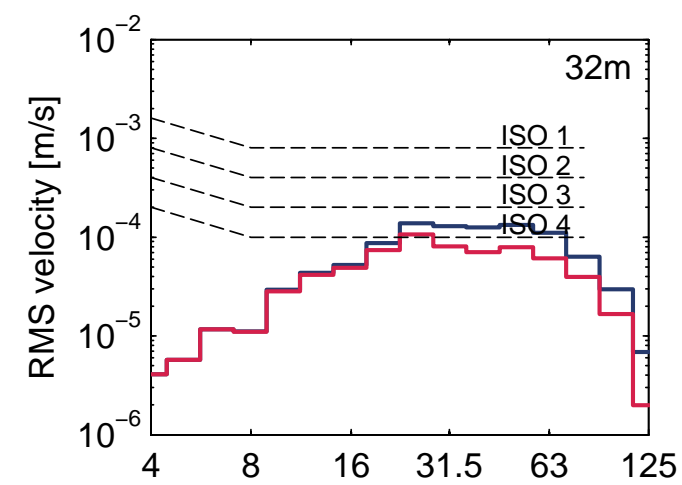

(d) $1 / 3$ octave band center frequency $[\mathrm{Hz}]$

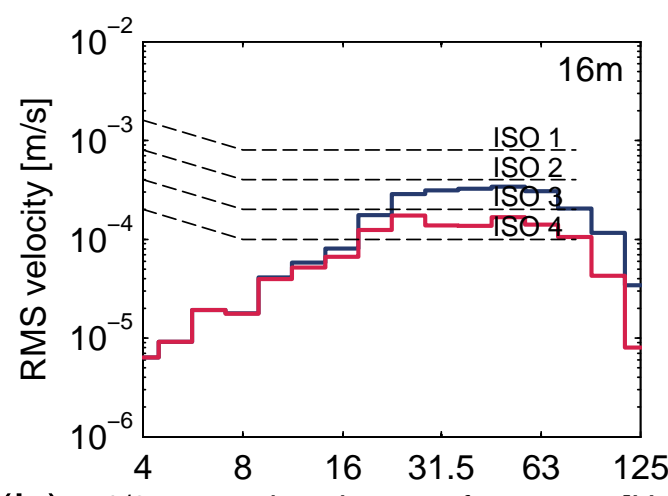

(b)

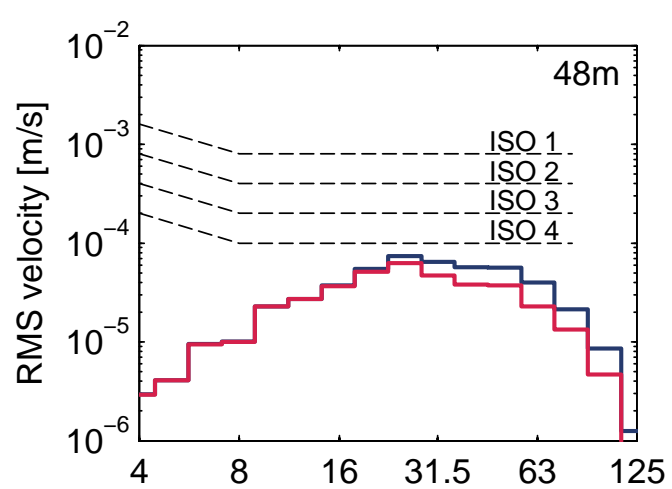

(e)

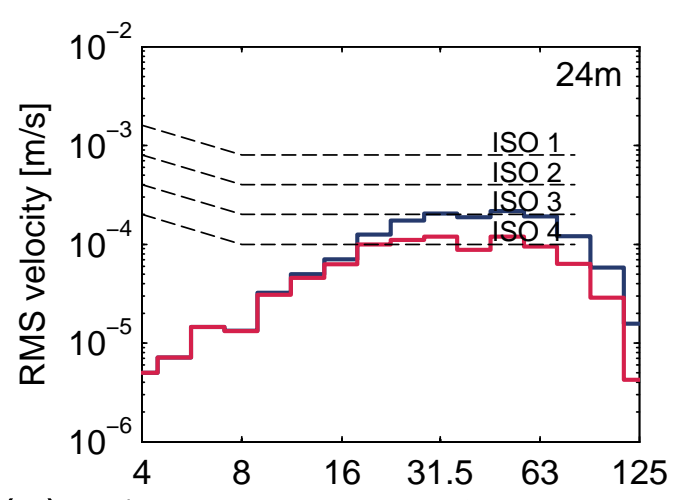

(C) $1 / 3$ octave band center frequency $[\mathrm{Hz}]$

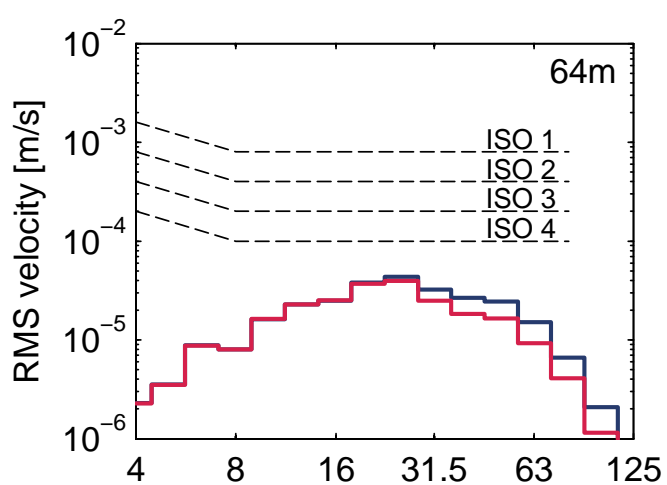

(f) $1 / 3$ octave band center frequency [Hz] 


\section{Train passage}

\section{Passage of a Renfe S599 train at $160 \mathrm{~km} / \mathrm{h}$}

- Vertical insertion loss $\widehat{\mathrm{IL}}_{z}(\mathbf{x}, \omega)$ at $8 \mathrm{~m}, 16 \mathrm{~m}, 24 \mathrm{~m}, 32 \mathrm{~m}, 48 \mathrm{~m}$ and $64 \mathrm{~m}$ from the center of the track (black to light grey lines) due to the passage of a Renfe $S 599$ at a speed of $160 \mathrm{~km} / \mathrm{h}$ :

$-\widehat{\mathrm{IL}}_{z}\left(x_{1}, \bar{\omega}\right)>\widehat{\mathrm{IL}}_{z}\left(x_{2}, \bar{\omega}\right)$ with $x_{1}<x_{2}$

$-\widehat{\mathrm{IL}}_{z}\left(\bar{x}, \omega_{1}\right)<\widehat{\mathrm{IL}}_{z}\left(\bar{x}, \omega_{2}\right)$ with $\omega_{1}<\omega_{2}$

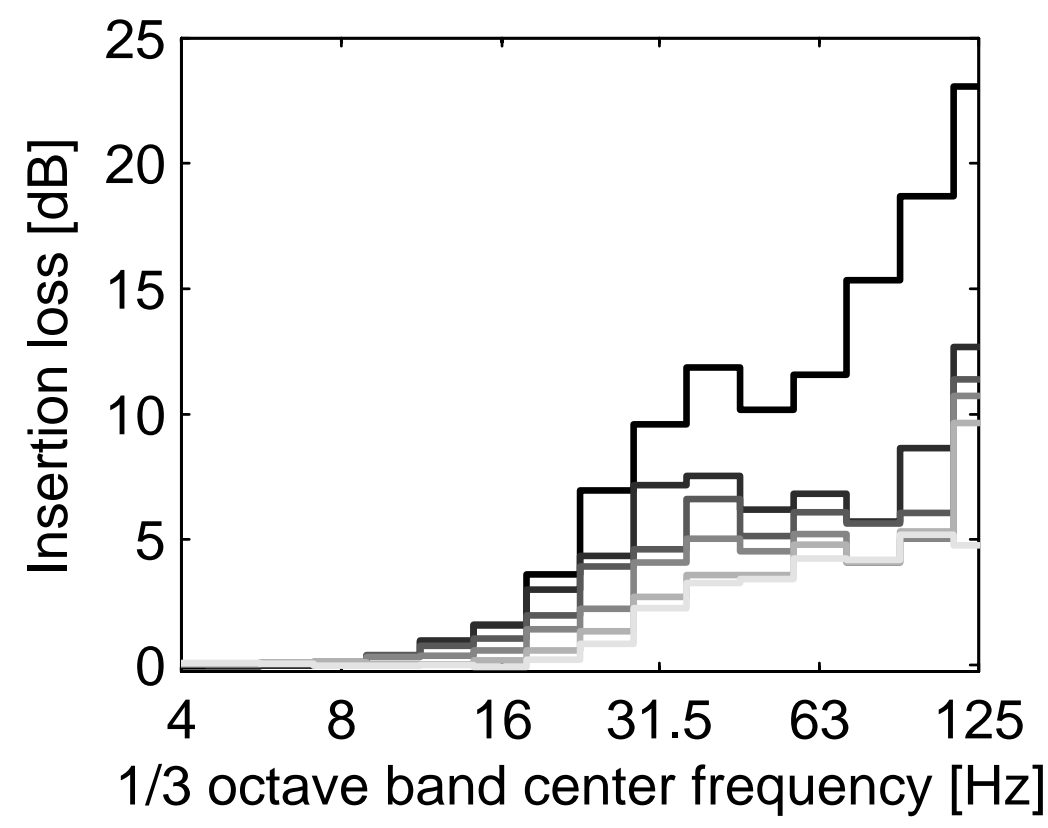




\section{Test site}

\section{EI Realengo test site}

- El Realengo test site in Spain: low Segura river flood plain.

- Conventional railway line (ADIF) between Murcia and Alicante

- A jet grouting wall of $1 \mathrm{~m} \times 55 \mathrm{~m} \times 7.5 \mathrm{~m}$ has been constructed
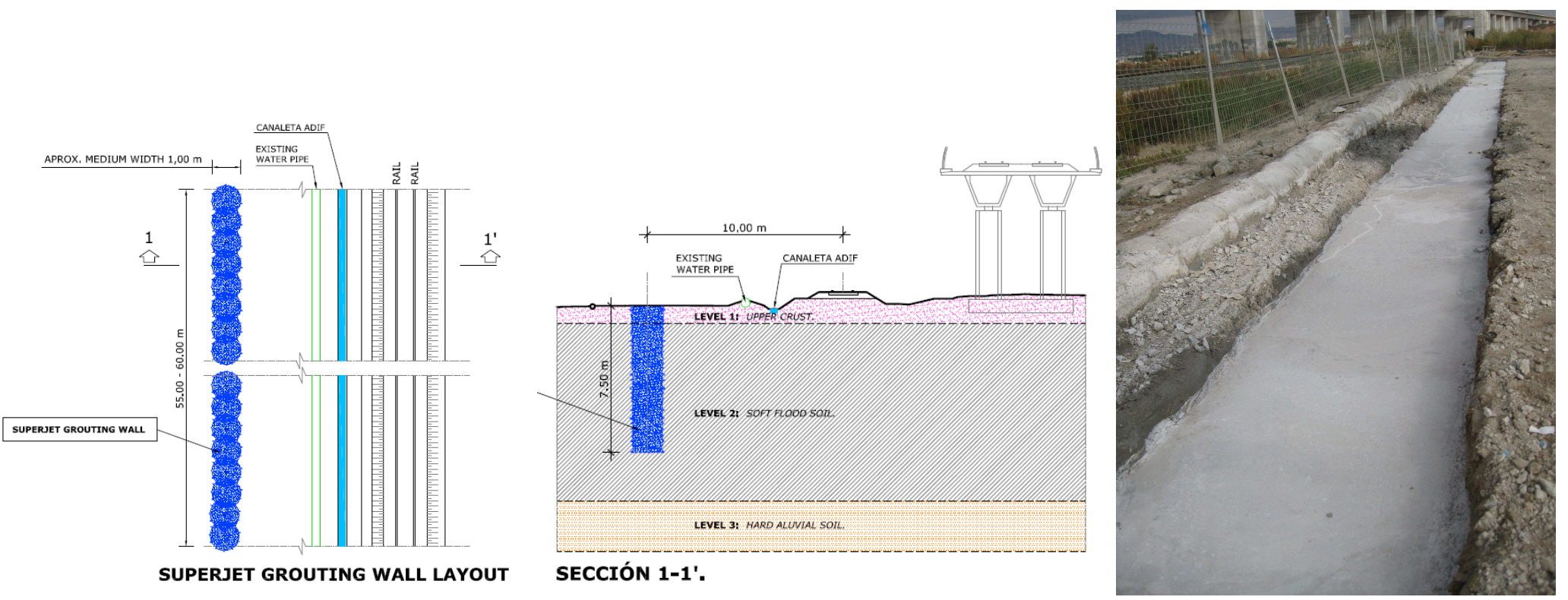

- An extensive measurement campaign will be carried out to verify the effectiveness of the jet grouting wall 


\section{Sheet piling wall}

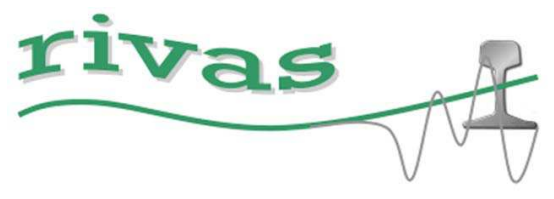

\section{Furet}

- Located in southwest of Sweden along the West Coast Line between Gothenburg and Lund

- Vibration problems in houses nearby $(4-5 \mathrm{~Hz})$

\section{Sheet piling wall $(100 \mathrm{~m})$}

- VL 603-K profiles with depth of $12 \mathrm{~m}$, every fourth pile extended to $18 \mathrm{~m}$
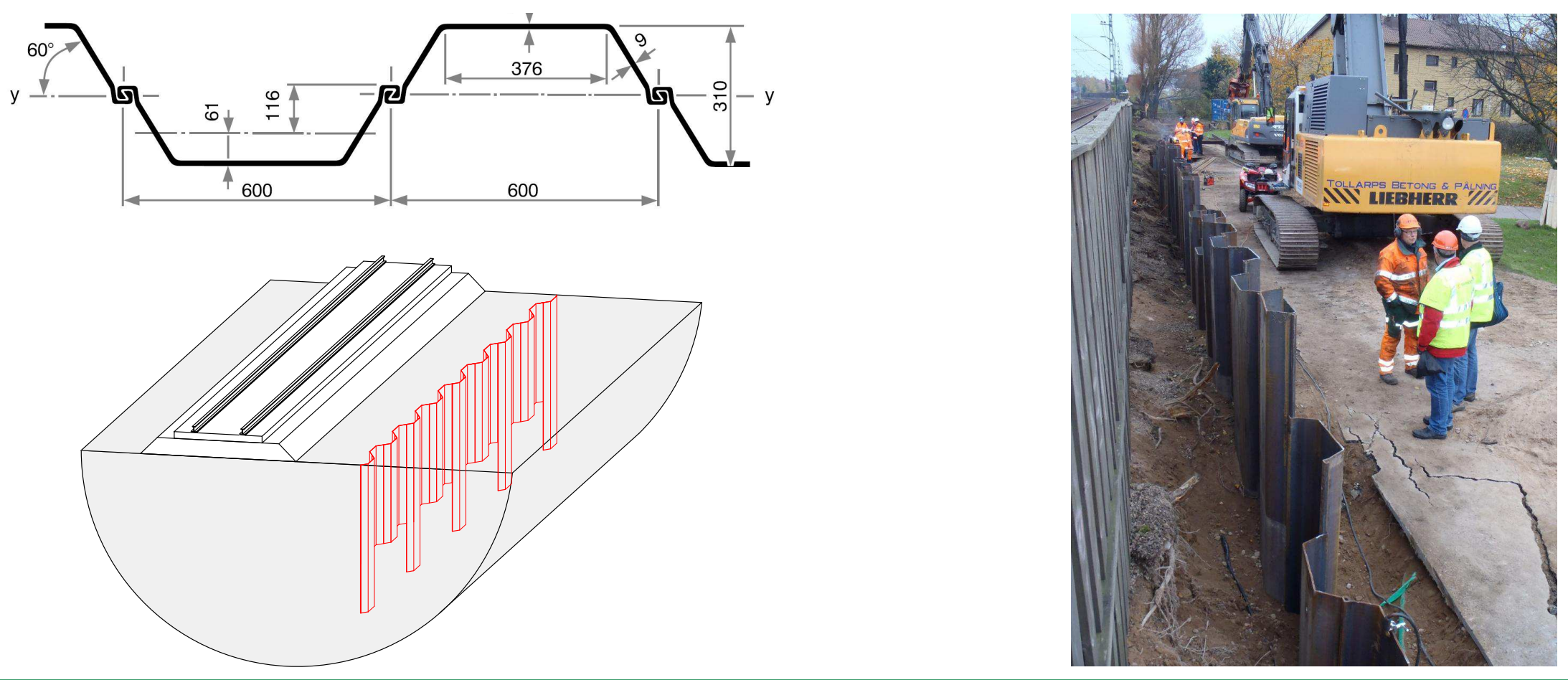


\section{Sheet piling wall model}

\subsection{D methodology}

- Longitudinally invariant geometry

- Two models: depth $12 \mathrm{~m}$ and $18 \mathrm{~m}$

- Profiling
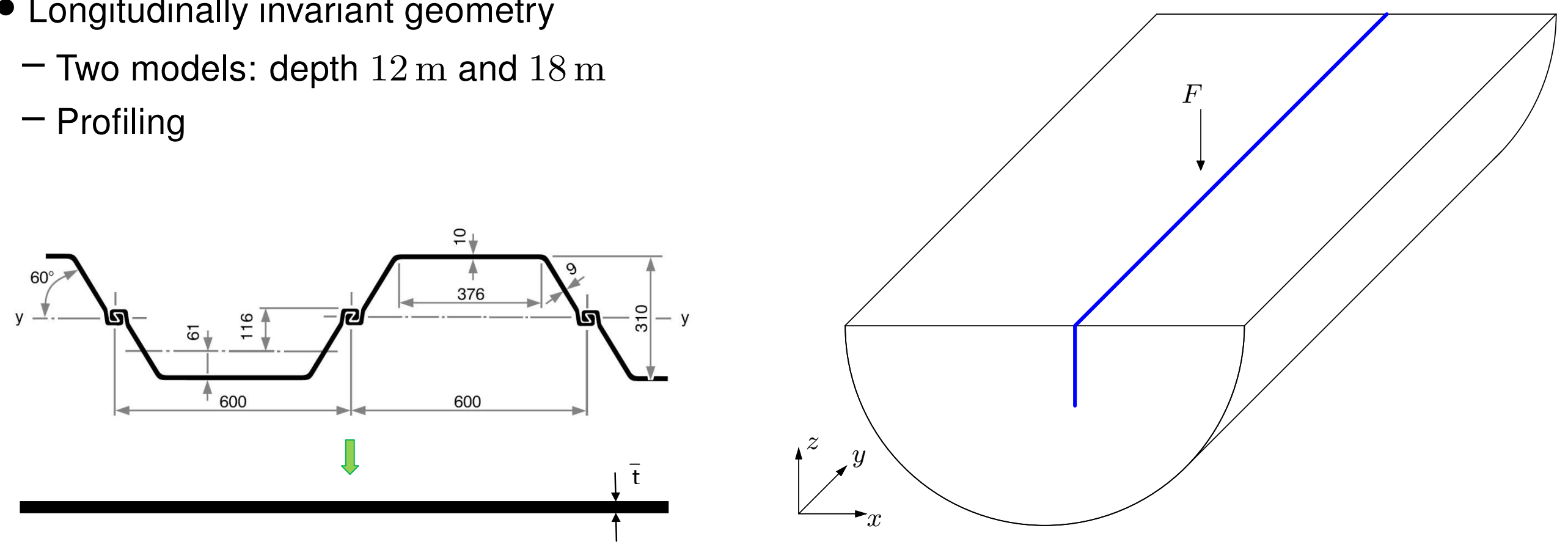

\section{Equivalent orthotropic plate model}

- Bending stiffness along the profiles $B_{z}$ is much larger than bending stiffness perpendicular to the profiles $B_{y}$ 


\section{Homogeneous halfspace}

\section{Dynamic soil characteristics (Horstwalde)}

\begin{tabular}{lcccccc}
\hline Layer & $\begin{array}{c}C_{\mathrm{s}} \\
{[\mathrm{m} / \mathrm{s}]}\end{array}$ & $\begin{array}{c}C_{\mathrm{p}} \\
{[\mathrm{m} / \mathrm{s}]}\end{array}$ & $\begin{array}{c}\beta_{\mathrm{s}} \\
{[-]}\end{array}$ & $\begin{array}{c}\beta_{\mathrm{p}} \\
{[-]}\end{array}$ & $\begin{array}{c}\rho \\
{\left[\mathrm{kg} / \mathrm{m}^{3}\right]}\end{array}$ & $\begin{array}{c}\nu \\
{[-]}\end{array}$ \\
\hline Halfspace & 250 & 1470 & 0.025 & 0.025 & 1945 & 0.485 \\
\hline
\end{tabular}

Vertical displacement and corresponding IL at $25 \mathrm{~Hz}$

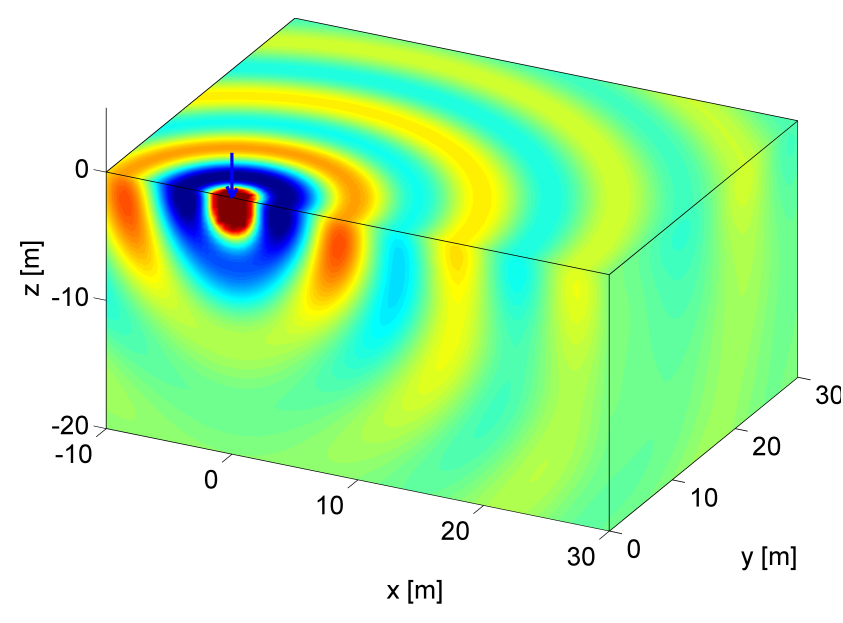

$x[\mathrm{~m}]$

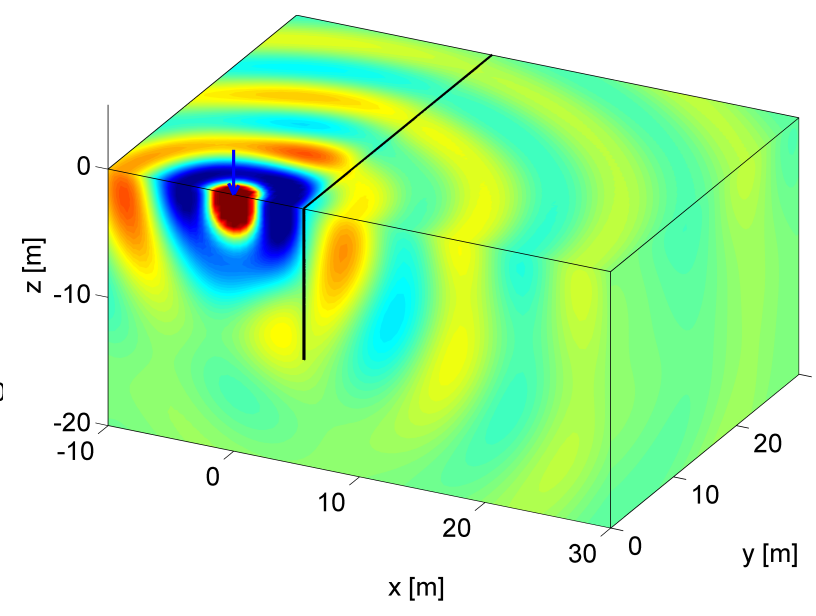

$x[m]$

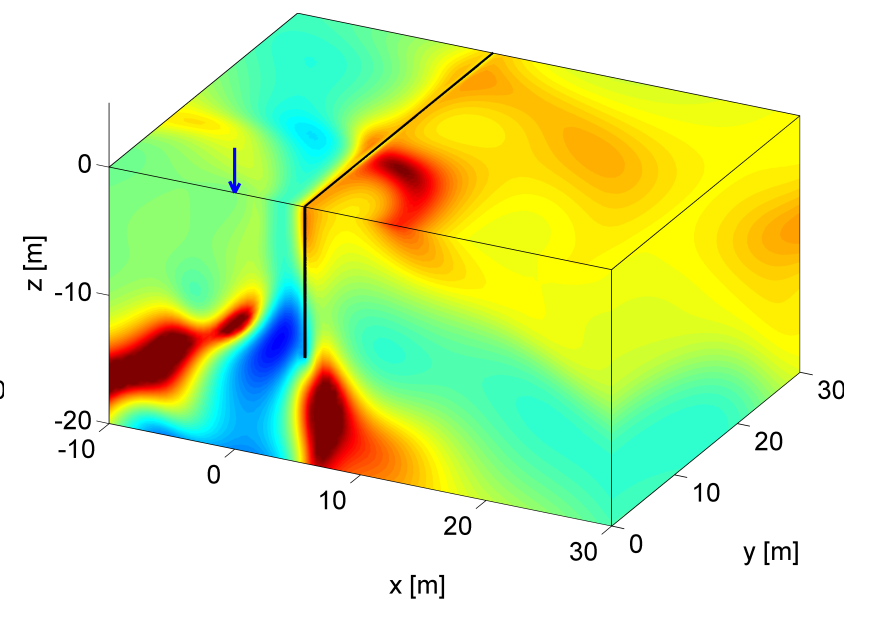

Insertion loss $[\mathrm{dB}]$ 


\section{Homogeneous halfspace}

\section{Wave impeding effect due to longitudinal bending stiffness}

- Longitudinal bending waves with bending around $x$-axis are not excited due to limited width

- Longitudinal bending waves with bending around $z$-axis do not play a role due to low bending stiffness

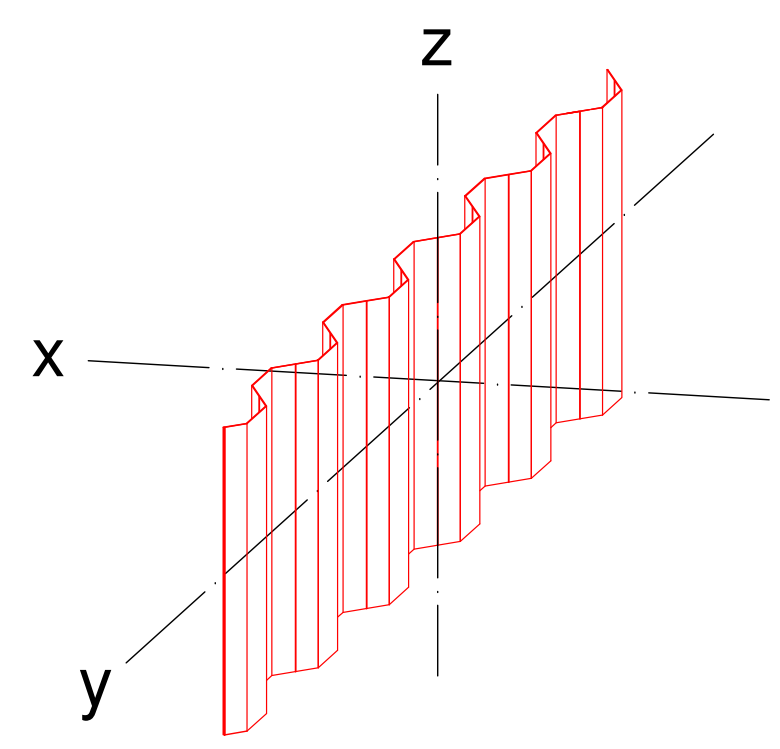




\section{Homogeneous halfspace}

\section{Wave impeding effect due to longitudinal bending stiffness}

- Longitudinal bending waves with bending around $x$-axis are not excited due to limited width

- Longitudinal bending waves with bending around $z$-axis do not play a role due to low bending stiffness

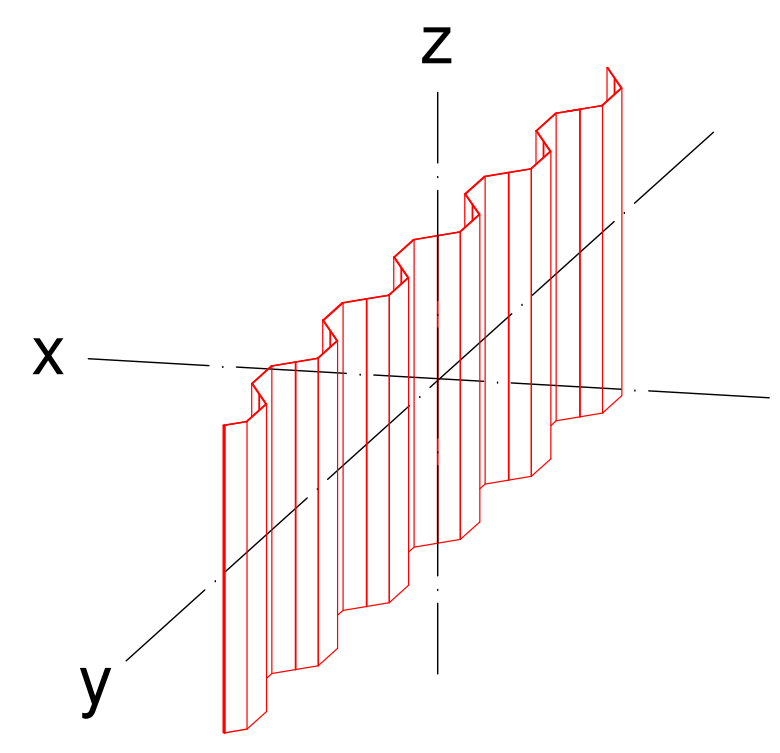

Wave impeding effect due to reflection of Rayleigh waves

- When the depth of the wave barrier is large enough compared to the Rayleigh wave length

- Rule of thumb: $d>0.75 \lambda_{\mathrm{R}}$

- Almost independent of angle of incidence 


\section{Furet test site}

\section{Dynamic soil characteristics}

- Geotechnical and geophysical surveys

- Soil profile

\begin{tabular}{lccccccc}
\hline Layer & $h$ & $C_{\mathrm{s}}$ & $C_{\mathrm{p}}$ & $\beta_{\mathrm{s}}$ & $\beta_{\mathrm{p}}$ & $\rho$ \\
{$[\mathrm{m}]$} & {$[\mathrm{m} / \mathrm{s}]$} & {$[\mathrm{m} / \mathrm{s}]$} & {$[-]$} & {$[-]$} & $\begin{array}{c}\rho \\
{\left[\mathrm{kg} / \mathrm{m}^{3}\right]}\end{array}$ & $\begin{array}{c}\nu \\
{[-]}\end{array}$ \\
\hline 1 & 2.0 & 154 & 375 & 0.025 & 0.025 & 1800 & 0.40 \\
2 & 10.0 & 119 & 290 & 0.025 & 0.025 & 1850 & 0.40 \\
Halfspace & $\infty$ & 200 & 490 & 0.025 & 0.025 & 1710 & 0.40 \\
\hline
\end{tabular}
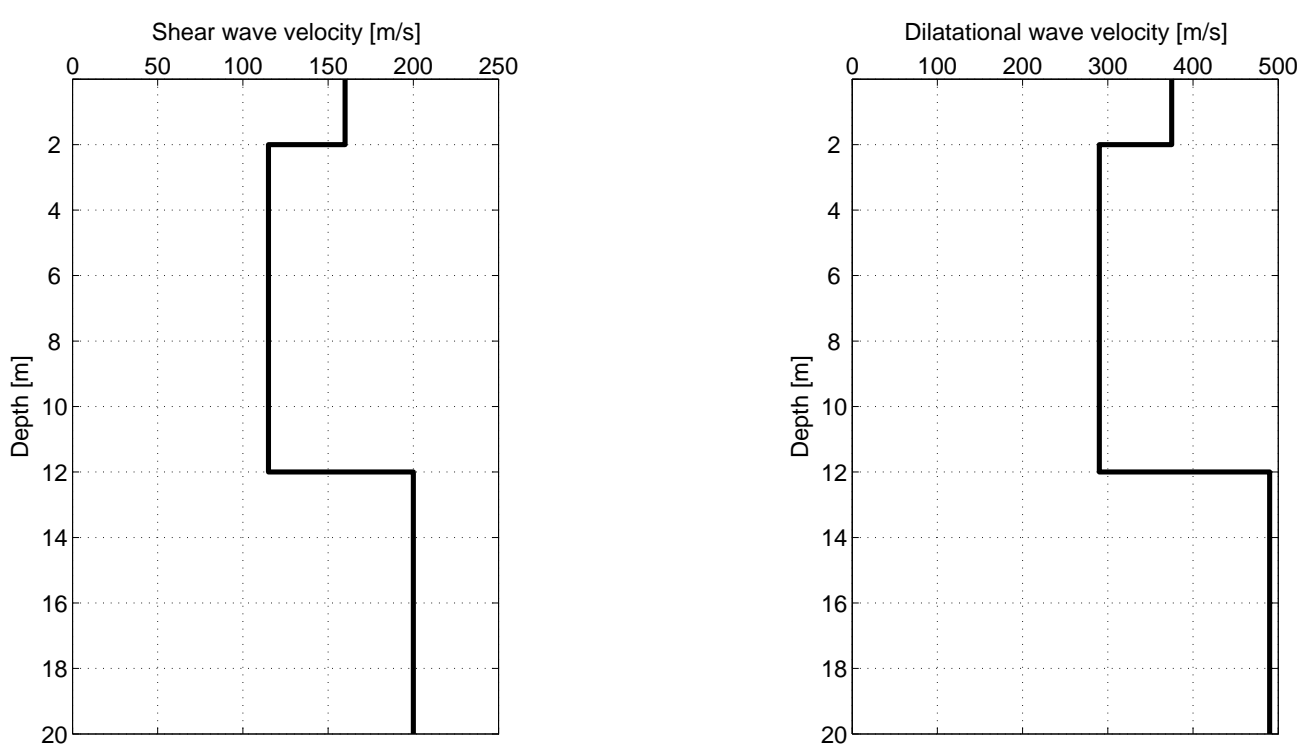


\section{Furet test site}

\section{Fundamental Rayleigh wave}

- Real (solid line) and imaginary (dashed-dotted line) part of the fundamental Rayleigh wave at $5 \mathrm{~Hz}$

- Real (solid line) and imaginary (dashed-dotted line) part of the fundamental Rayleigh wave at $25 \mathrm{~Hz}$
Horizontal component
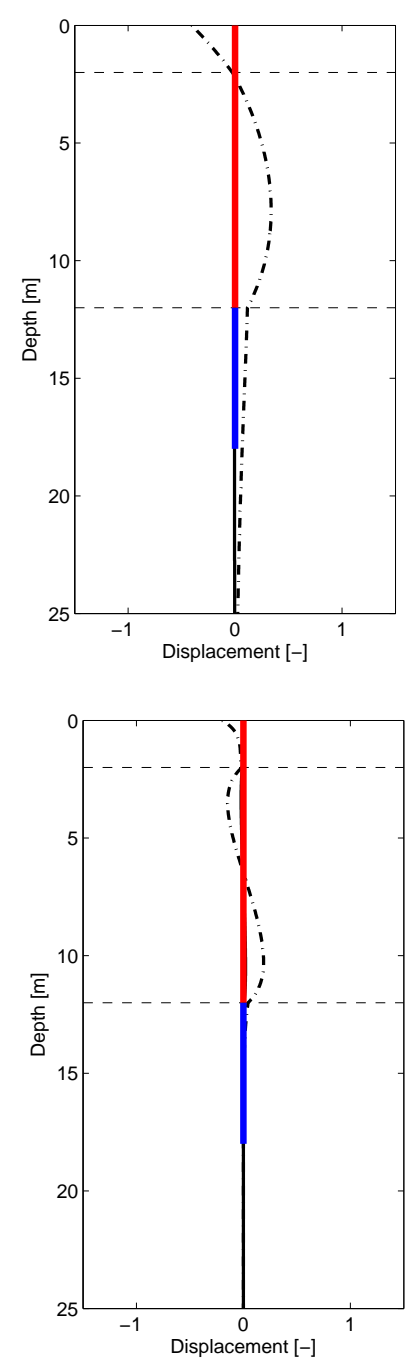

Vertical component
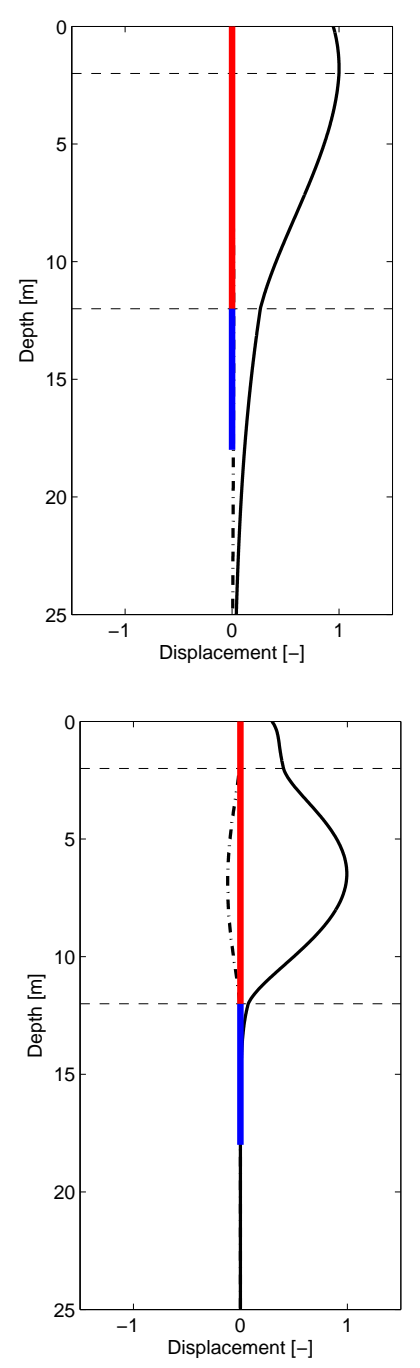


\section{Furet test site}

- Vertical insertion loss for a $12 \mathrm{~m}$ deep sheet pile wall at $5 \mathrm{~Hz}$ (left) and $25 \mathrm{~Hz}$ (right)
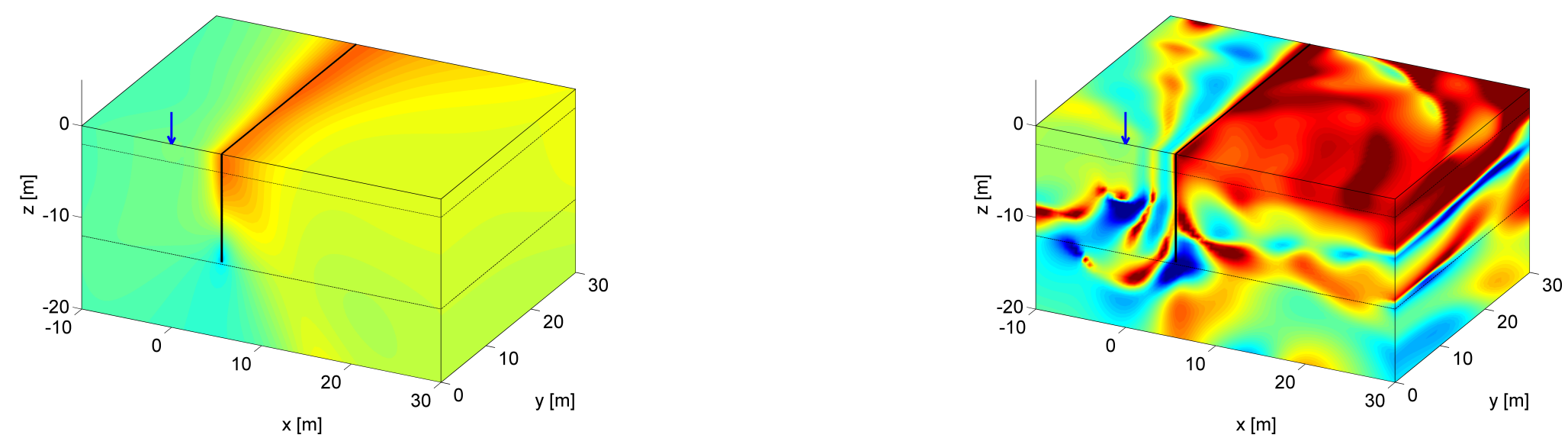

- Vertical insertion loss for a $18 \mathrm{~m}$ deep sheet pile wall at $5 \mathrm{~Hz}$ (left) and $25 \mathrm{~Hz}$ (right)
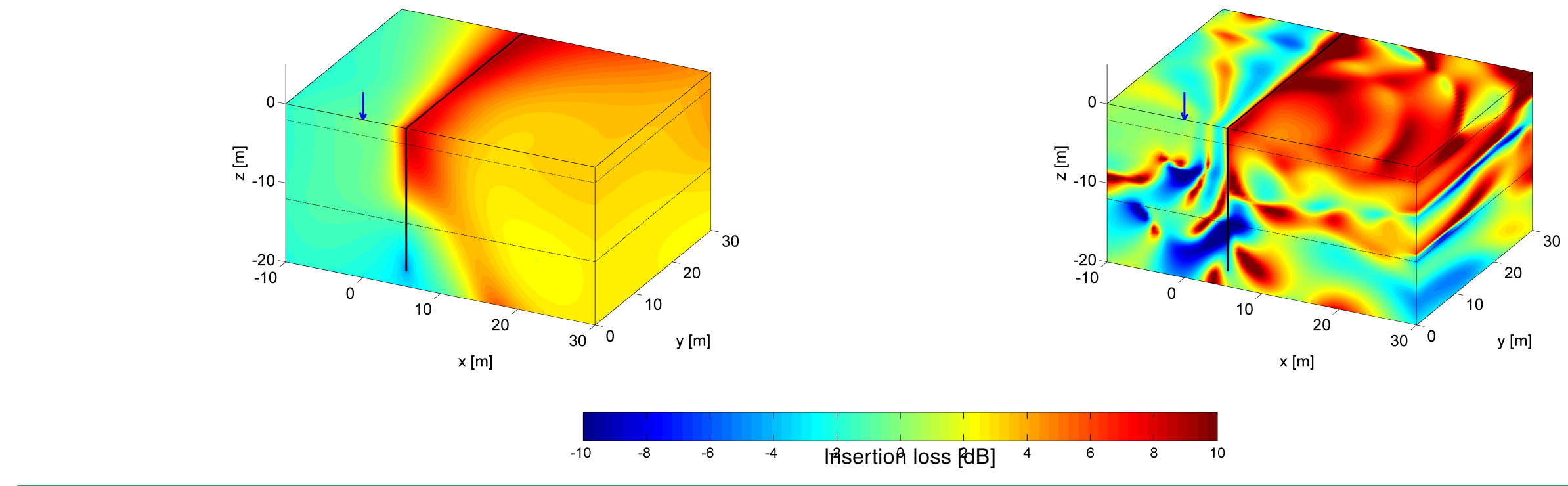


\section{Furet test site}

\section{Vertical insertion loss for a line load}

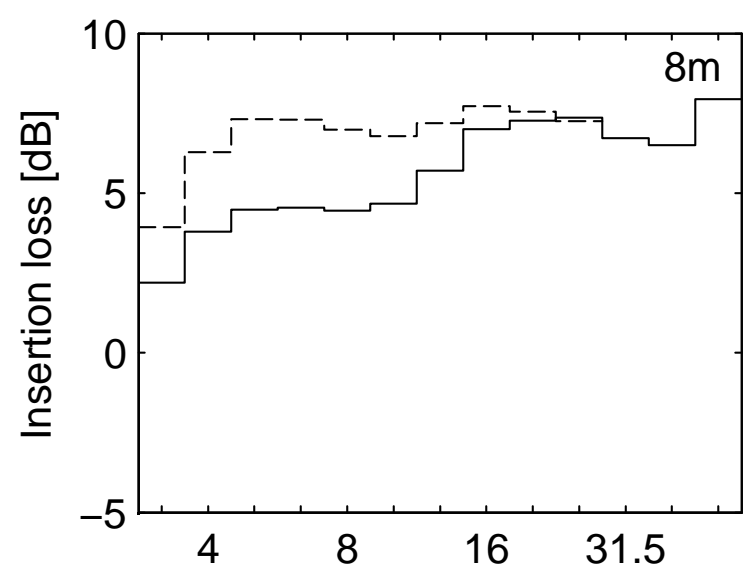

$1 / 3$ octave band center frequency $[\mathrm{Hz}]$
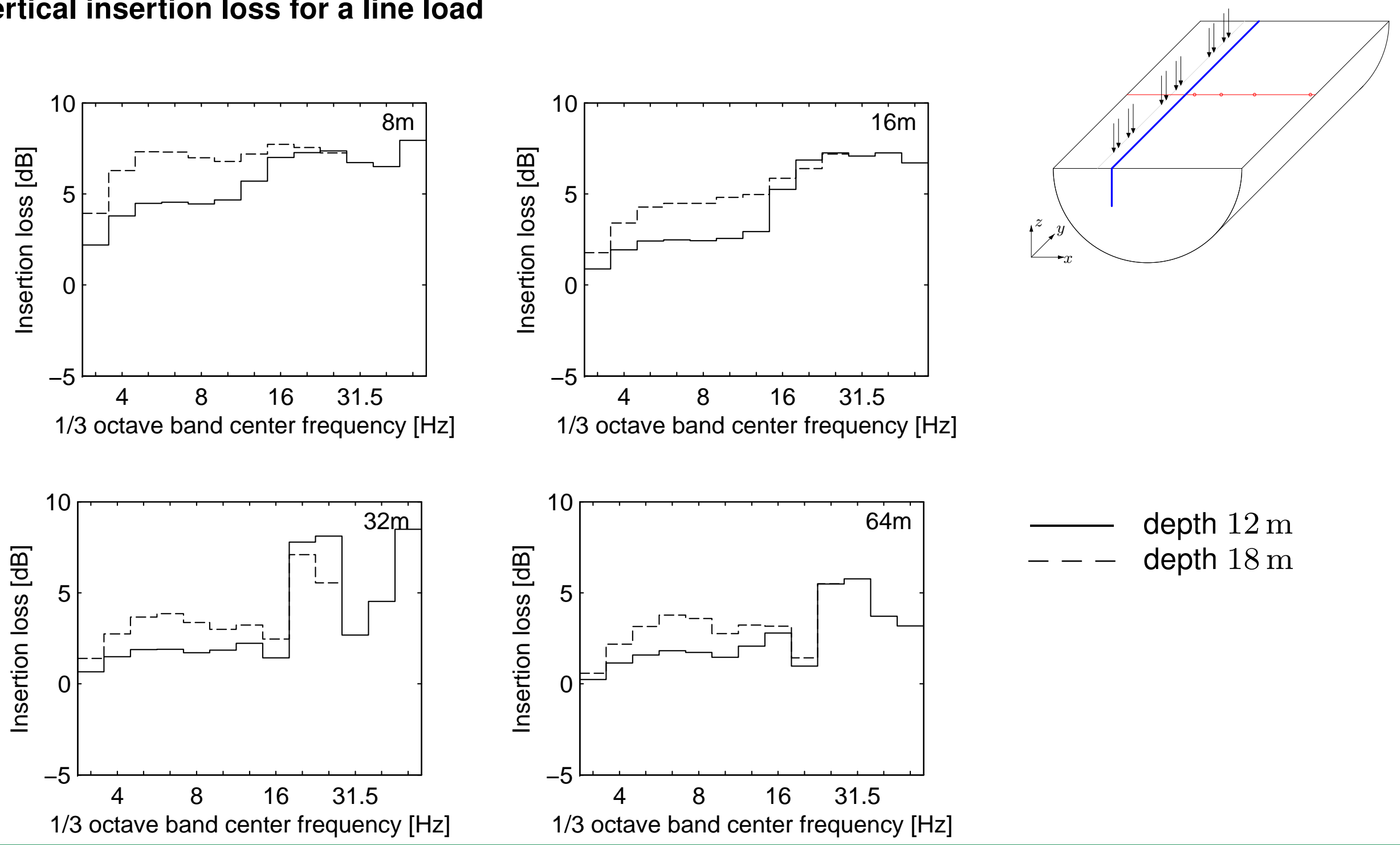

- depth $12 \mathrm{~m}$

- - - depth $18 \mathrm{~m}$ 


\section{Conclusions and outlook}

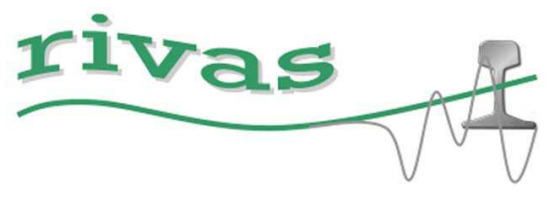

\section{Conclusions}

- Two phenomena contribute to the vibration reduction efficiency of a stiff wave barrier:

- interaction between Rayleigh waves in the soil and bending waves in the barrier (jet grouting wall)

- reflections of Rayleigh waves if the barrier depth is large compared to the Rayleigh wavelength (sheet piling wall)

\section{Outlook}

- Comparison between simulations and measurements (jet grouting wall and sheet piling wall)

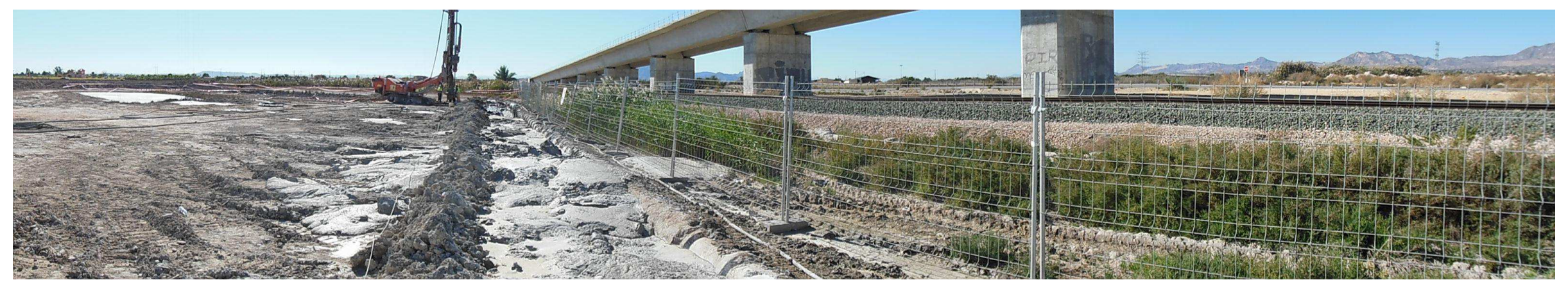

- A design guide with practical recommendations (RIVAS Deliverable D4.6) will be made publicly available 


\title{
Thank you for your attention
}

\author{
Visit our website www.rivas-project.eu
}

